\title{
Anaglif Representation of Polar Motion over the Last Century
}

\author{
S. Nagy \\ FÖMI Satellite Geodetic Observatory, P.O. Box 546, H-1373 Budapest, \\ Hungary
}

This is a special demonstration of the polar motion over the last century. Our figures represent the $\left(x_{p}, y_{p}\right)$ coordinates of Earth's axis, and the elapsed time along the $z$-axis. The figures remind us of a spiral spring. For the sake of illustration we used the so-called anaglif projection. Red and green glasses must be used to see the figures. The whole century (1899-1999) is too long for one diagram. So we divided the database into ten parts and present ten figures. The historic data was taken from IERS EOP C01 database and the new data from the IERS Bulletin B $(1997,1998)$. The EOP C01 database contains only twenty $\left(x_{p}\right.$, $y_{p}$ ) pairs per year. This is not sufficient for the refined representation, therefore we used the cubic spline interpolation for densification. The ten figures presented provide a quick review of the history of the polar motion over the last century: small amplitude in the twenties and thirties, with powerful fluctuation in the fifties. It is remarkable how the spiral leaves the Conventional International Origin (CIO) westwards due to the secular polar motion.

Remark: a series of figures is available upon request from the author (e-mail: nagy@sgo.fomi.hu).

\section{References}

Carnera, L. 1957, Risultati del Servizio Internazionale delle Latitudini dal 1935.0 al 1941.0, UNESCO.

Gaposhkin, E.M. 1972, Analysis of Pole Position from 1846 to 1970 in: Melchior, P., Yumi, S. (eds.) Rotation of the Earth, Proc. IAU Symp. 48., 19, Dordrecht: Reidel.

IERS, 1997, Annual Report 1996, Paris: Observatoire de Paris.

Kimura, H., 1940, Results of the International Latitude Service from 1922.7 to 1935.0, Mizusawa: IAU.

Pál, I., 1973, Spatial geometry in practice, Budapest: Tankönyvkiadó (in Hungarian).

Závoti, J., 1979, Application of spline functions, Budapest: MTESZ (in Hungarian). 


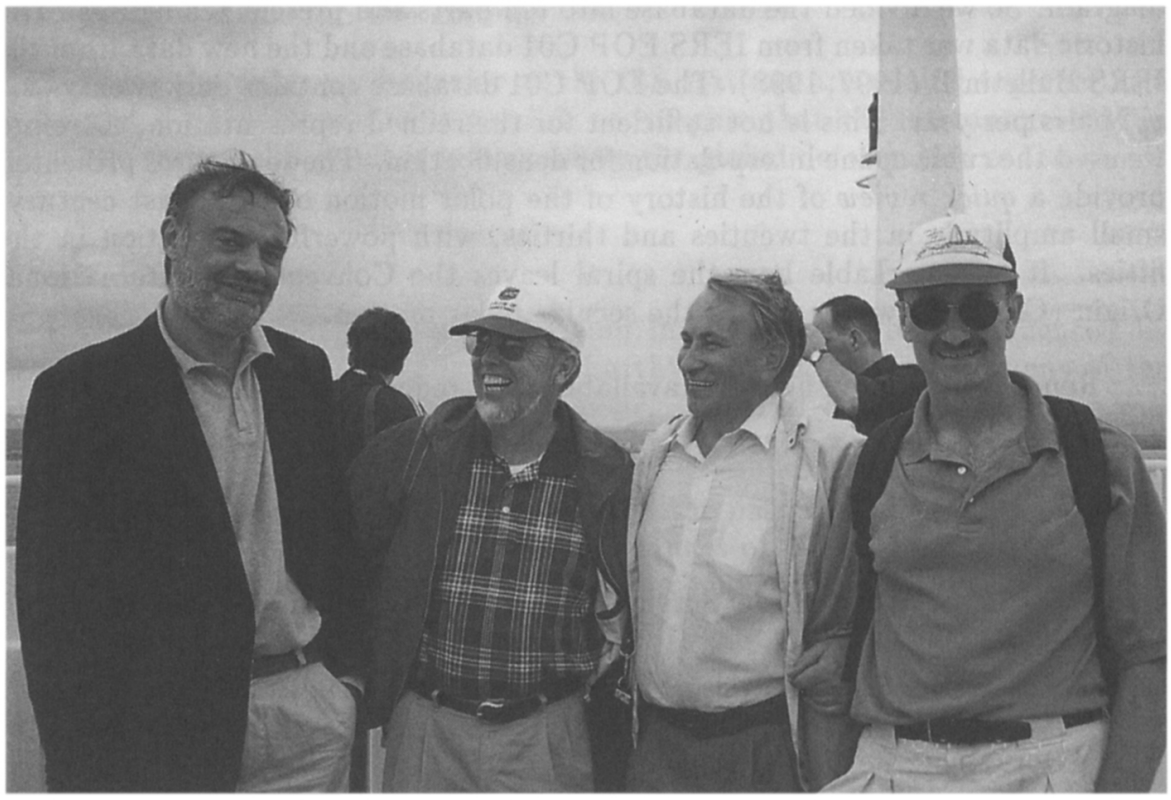

Flavio Fusi Pecci, Bill Carter, Yaroslav Yatskiv, and Clark Wilson 